needs evaluation as an independent performance/quality indicator of acute NIV services.

\section{P298 REFERRAL PATTERNS AND MORTALITY IN A NON- INVASIVE VENTILATION (NIV) UNIT IN A TERTIARY UNIVERSITY HOSPITAL IN THE UK}

K Aldridge, S Bikmalla, A Thomas. University Hospital of North Staffordshire, Stoke-onTrent, UK

\subsection{6/thoraxjnl-2014-206260.416}

Introduction NIV for acute hypercapnic respiratory failure (AHRF) in COPD and restrictive lung disease has become widespread in the UK. Early institution of NIV in appropriate patients gives the best outcome.

Methods We retrospectively examined referral patterns to our tertiary 12 bedded NIV unit during a 12 month period from November 2012 to October 2013. Admission criteria to the unit is standardised and through the NIV consultant or senior nursing staff. Site of referral was noted and mortality rate was calculated.

Results 612 referrals were made to the dedicated NIV unit in the 12 months. 125 were elective admissions for setting up domiciliary NIV and were excluded from the mortality analysis as there was no mortality in this group. The overall mortality for the rest of the cohort was $15.2 \%$ of the remaining 487 patients acutely admitted to the unit. The source of referrals to the unit was varied and as shown in Figure 1. The mortality rate for admissions from the acute portals ( $\mathrm{A}$ and $\mathrm{E}$ and the Acute Medical unit) were significantly lower (10.4\%) than from the medical wards (23\%). This reflects the fact that even with a well selected cohort the timing of the respiratory failure in the course of illness plays an important part in determining mortality. We know that uncorrected respiratory acidosis after $4 \mathrm{~h}$ of NIV is a strong determinant of mortality. The highest mortality (64.5\%) was seen of referrals from the Frail elderly unit. This also shows that general constitution plays an important role in mortality.

Conclusion Early referral for NIV support in AHRF improves outcomes. Delayed hypercapnic respiratory failure and frailty are important factors determining poorer outcomes.

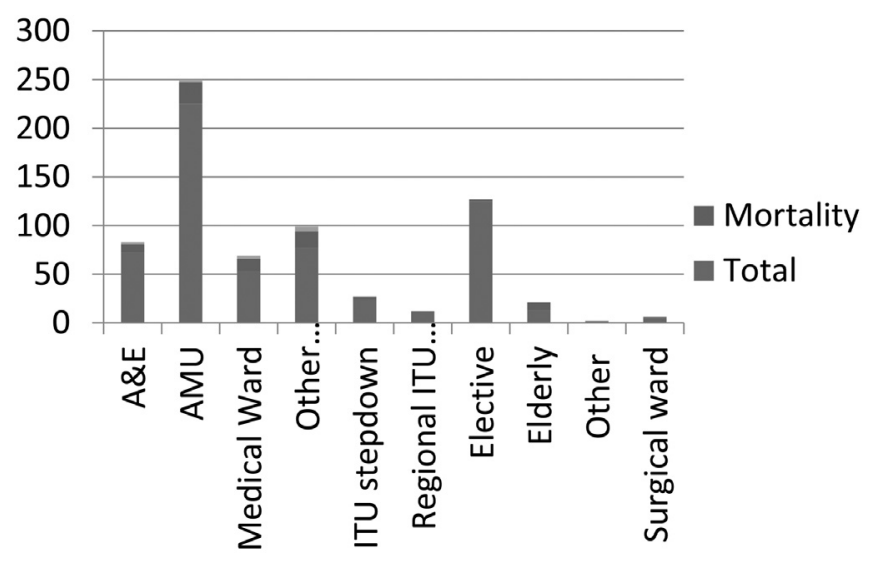

Abstract P298 Figure 1
P299 THE ROLE OF A MULTIDISCIPLINARY RESPIRATORY HUB IN IMPROVING POST-DISCHARGE FOLLOW UP OF PATIENTS RECEIVING ACUTE NON-INVASIVE VENTILATION (NIV)

${ }^{1} \mathrm{~F}$ Rauf, ${ }^{1} \mathrm{~A}$ Oakes, ${ }^{1} \mathrm{Y}$ Khan, ${ }^{1} \mathrm{~T}$ Stuart, ${ }^{2} \mathrm{~B}$ Chakraborty, ${ }^{3} \mathrm{AM}$ Turner, ${ }^{1} \mathrm{R}$ Mukherjee. ${ }^{1}$ Birmingham Heartlands Hospital, Birmingham, UK; ${ }^{2}$ School of Mathematics, University of Birmingham, Birmingham, UK; ${ }^{3}$ College of Medical and Dental Sciences, University of Birmingham, Birmingham, UK

10.1136/thoraxjnl-2014-206260.417

Introduction Post-discharge follow up rate is a national audit metric for acute NIV services in the UK [Davies M. Adult NIV Audit report. BTS Reports 2012. 4 (3): 9-10.]. Appropriate respiratory follow up reduces the number of re-admissions [Turner AM et al. Prim Care Respir J 2013; 22(1):72-78.] In order to improve post-discharge follow ups, a rapid access one-stop multidisciplinary respiratory outpatient Hub was created at our 709bedded acute hospital in October 2011.

Methods From the acute NIV database maintained continuously since 2004 , we analysed the proportion of discharges that were offered respiratory follow up within 6 months of discharge after Acute NIV during the calendar year 2009 (pre-Hub) and first 6 months of 2013 (post-Hub). Chi-squared test was performed for statistical significance of the observed differences.

Results The proportion of unique discharges offered a follow up appointment at the time of discharge improved from 57\% (62/ 107) pre-Hub to $80 \%(36 / 45)$ post-Hub: $\mathrm{p}=0.009$. The proportion of patients attending follow-up appointments increased from $40 \%(42 / 107)$ pre-Hub to $58 \%$ (26/45) post-Hub: $\mathrm{p}=$ 0.036 , confirming a statistically significant improvement. The number of acute NIV re-admissions dropped between 2009 and 2013 but expectedly not statistically significant, as only 6 months' data from the post-Hub period was analysed against 12 months of data from the pre-Hub period.

Conclusions The increase in the number of patients attending post-discharge NIV follow up correlates with the direct increase in the number being offered follow up, an improvement most obviously measuring the impact of the multidisciplinary 'Hub'. The Hub would also be the most plausible explanation for the drop in acute NIV re-admissions between the 2 periods, not the least because apart from a 'routine' follow-up, it supports community teams and provides an alternative to ambulance calls to people with complex respiratory needs in a responsive fashion. Further longitudinal evaluation of the Multidisciplinary Hub is necessary to fully understand its impact on the quality and safety of complex respiratory care.

\section{P300 THE CLINICAL EFFECTIVENESS OF DOMICILIARY NON- INVASIVE VENTILATION (NIV) IN PATIENTS WITH END- STAGE COPD}

${ }^{1}$ J Dretzke, ${ }^{2} \mathrm{C}$ Dave, ${ }^{1} \mathrm{D}$ Blissett, ${ }^{2} \mathrm{R}$ Mukheriee, ${ }^{1} \mathrm{M}$ Price, ${ }^{1} \mathrm{~S}$ Bayliss, ${ }^{1} \mathrm{X} W u$, ${ }^{1} \mathrm{R}$ Jordan, ${ }^{1} \mathrm{~S}$ Jowett, 'DJ Moore, 'AM Turner. 'University of Birmingham, Birmingham, UK; ${ }^{1}$ Heart of England NHS Foundation Trust, Birmingham, UK

10.1136/thoraxjnl-2014-206260.418

Background NIV is very effective when used acutely in hospital during acute exacerbations of COPD, however, evidence supporting its use in a home setting for more stable COPD patients is limited. In the UK domiciliary NIV is considered by many 